Floresta e Ambiente 2021; 28(4): e20210026

https://doi.org/10.1590/2179-8087-FLORAM-2021-0026

ISSN 2179-8087 (online)

\title{
Wood Quality of Young Teak in Different Planting Spaces
}

Juliana Bernardo Amodei ${ }^{1}$ (1)

João Vicente de Figueiredo Latorraca ${ }^{1}$ (C)

Glaycianne Christine Vieira dos Santos ${ }^{1}$ (1)

Bianca Cerqueira Martins ${ }^{2}$ (D)

${ }^{1}$ Universidade Federal Rural do Rio de Janeiro, Instituto de Florestas, Seropédica, RJ, Brasil.

${ }^{2}$ Universidade Federal do Acre, Rio Branco, AC, Brasil.

\begin{abstract}
Wood quality is related to the characteristics and properties of this material. Understanding the factors that can impact the wood formation is fundamental in the indications for use. The aim of this study was to evaluate the influence of different planting densities on the wood quality and the radial profile on some physical and anatomical characteristics of young trees of Tectona grandis. Nine trees were evaluated in three planting densities: $6 \times 2 \mathrm{~m}$; $5 \times 2 \mathrm{~m}$; and $4 \times 2 \mathrm{~m}$. All trees were subjected to analysis of acoustic tomography, X-ray densitometry, and fiber characterization. Multivariate associations between the variables of interest were evaluated according to the planting spacing and the radial profile by principal component analysis. The results indicated that the wood characteristics of young teak trees are influenced, mainly, by the radial variation (pith-bark).
\end{abstract}

Keywords: Impulse tomography, X-ray densitometry, Principal component analysis, Tectona grandis, Wood anatomy.

\section{INTRODUCTION AND OBJECTIVES}

Tectona grandis L. f., popularly known as teak, is a deciduous and pioneer species belonging to the Lamiaceae family. It is considered one of the most valuable tropical timber species, whose wood is in high demand in the luxury markets, in the civil industry, and in the manufacture of furniture (Kollert \& Kleine, 2017). It occurs naturally in four countries in South and Southeast Asia, namely Myanmar, India, Lao People's Democratic Republic, and Thailand. In 2010, these countries had approximately 29 million hectares in natural teak forests, among which Myanmar stood out with approximately half of that area (Kollert \& Cherubini, 2012). However, it is estimated that forest areas have been gradually reduced over the past few years, due to deforestation, agricultural expansion, mining, forest fires, among others (Khaing et al., 2017), highlighting the need for investments in clonal and seminal planted forests. In Brazil, in 2018, teak plantations occupied $15.89 \%$ of the total area with unconventional forest crops, representing the third-largest crop in extension (IBÁ, 2019).

Teak wood has high quality due to its moderate density and strength, high dimensional stability, and durability.
Such characteristics are associated with the formation of the heartwood, which occurs between 4 and 5 years of age, in this species (Thulasidas \& Baillères, 2017). Among the factors that influence the heartwood properties and, consequently, the wood quality, the following stand-out age, longitudinal variation, geographic location, environmental conditions, and silvicultural treatments (Moya et al., 2014).

Studies on the silvicultural treatments suitable for each species are important for the analysis of wood yield and quality, with emphasis on planting density or tree spacing (De Moraes Gonçalves et al., 2004). The available growth resources are directly influenced by the planting density, which in turn affects the growth and wood properties (Singh et al., 2020; Tun et al., 2018). Thus, optimizing the choice of this parameter contributes to the maximization of wood products according to the end-use.

One of the techniques with potential use for the evaluation of the internal structural integrity of the tree trunk is impulse tomography. The technique is based on the principle of the propagation of stress waves, generated mechanically. In general, the propagation speeds within the wood correlate with the density of the material and, therefore, provide relevant 
information about its quality (Mendes \& Silva Filho, 2019). Mechanical waves are better transmitted in intact wood when compared to those with some lesion-decomposing area or with the presence of cracks (Medeiros et al., 2017). In addition, the properties of wood (physical, chemical, and anatomical) can indirectly influence the wave propagation pattern, as they impact the density of the material.

Direct reading of the density variation along the wood can be obtained using the X-ray densitometry technique. The main equipment used is based on the principle of radiography in which an $\mathrm{x}$-ray beam passes through the analyzed material (Jacquin et al., 2017). In tree species with poorly defined growth rings, this technique can assist in identifying the limits of the growth rings and the construction of chronologies (Pagotto et al., 2017). In addition, it allows assessing the effects of forest management on the variation in wood quality (Makinen et al., 2015).

The application of these quick-reading techniques, combined with more traditional assessments, can provide relevant information on the effects of silvicultural treatments on the wood characteristics, being important in the planning and management of short-rotation plantations. Thus, this study aimed to evaluate the influence of different planting densities on the wood quality and the radial profile in the propagation of acoustic waves, apparent density, and anatomy in young trees of Tectona grandis.

\section{MATERIALS AND METHODS}

\subsection{Characterization of the study area}

The study material was collected in an 11-year-old teak stand located in the municipality of Cáceres, Mato Grosso, Brazil ( $\left.16^{\circ} 11^{\prime} 42^{\prime \prime} \mathrm{W} ; 57^{\circ} 40^{\prime} 51^{\prime \prime} \mathrm{S}\right)$. The wood of nine trees was evaluated, under three different planting densities: i) $6 \times 2 \mathrm{~m}$; ii) $5 \times 2 \mathrm{~m}$ and iii) $4 \times 2 \mathrm{~m}$ (three trees / spacing). Healthy trees, without apparent defects and with a straight $\log$ were selected.

The area is characterized by the original vegetation of forested savanna (cerradão) in a climate of tropical savannas with humid summer and dry winter (Aw, Köppen). It has a rainy tropical climate, with an average annual temperature between $23^{\circ} \mathrm{C}$ and $25^{\circ} \mathrm{C}$, a relatively high annual rainfall, but with a clear dry season, with annual temperature fluctuations below $5^{\circ} \mathrm{C}$. The relief is flat, and the soil is classified as a dystrophic Red-Yellow Latosol (Alvares et al., 2013).

All individuals received the same silvicultural treatments, which consisted of $20 \mathrm{~cm}$ tall stump seedlings, hand planting in $20 \times 20 \times 20 \mathrm{~cm}$ pits, fertilized with $190 \mathrm{~g}$ of simple superphosphate and $10 \mathrm{~g}$ of micronutrients FTE BR-15 (Frited Trace Elements). In the second and ninth months, 95g per plant of the formula 20-05-20 (N-P-K) were applied, plus $5 \mathrm{~g}$ per plant of FTE BR-15.

\subsection{Speed of acoustic waves propagation}

The propagation of acoustic waves, performed with the Impulse Tomography ARBOTOM ${ }^{\circledast}$ Rinntech, was evaluated at eight equidistant points, through the fixation of vibration sensors, along the circumference of the trunk of the selected trees. All sensors were fixed at $1.30 \mathrm{~m}$ from the ground, using metallic conductors oriented perpendicular to the axis of the tree; yet the diameters at this point (DBH) were measured. The transmission of the acoustic waves was carried out by tapping lightly on each sensor, using a hammer, until the error (delta\%) indicated by the equipment's software was less than $10 \%$.

From the time of propagation of acoustic waves, graphs of rainbow colors (tomograms) of the velocities of waves propagated in the wood were generated. The radial profile of the velocities was determined from the selection of a diametrical band, passing through the pith and which presented a greater color representation of the tomographic image. From that range, a line of pixels was traversed. The colors of the pixels in the line traveled were recognized with the aid of Adobe Photoshop software on the RGB scale, with a wave speed value associated with each color (Cavalcante Pereira et al., 2007).

The tomographic image is composed of variations in gray levels in each of the RGB bands (red, green, and blue, respectively), thus forming the colors of the image. These colors correspond to the propagation speed values of the mechanical wave. Through the identification of the respective values, a spreadsheet of colors and speeds was built for each of the tomographic images obtained. Thus, it was possible to identify the wave propagation speed in each element of the matrix and the construction of a speed graph for each evaluated range.

155 classes of mechanical wave propagation speed were adopted according to equation 1 , defining the speed interval by class and gray level values of the bands in each class (Rollo et al., 2013).

$S R=\frac{V-v}{155}$

Where $S R$ is the speed range $(\mathrm{m} / \mathrm{s}) ; \mathrm{V}$ is the maximum speed of propagation of the wave; and $\mathrm{v}$ is the minimum wave propagation speed. 


\subsection{Apparent density radial profile}

To obtain the radial density profile, the X-ray densitometry technique was used. Therefore, on each disk, a diametrical sample of the wood ( $2.0 \mathrm{~mm}$ thick) was obtained from the same position (diametrical range) where the propagation speed of the acoustic waves was analyzed. The cross-sections of the wood samples were stored in a climatic chamber $\left(20 \pm 1^{\circ} \mathrm{C}\right.$, $65 \pm 5 \% \mathrm{RH}$ ) until they reached $12 \%$ equilibrium humidity.

X-ray densitometry was performed using the QTRS01X Tree-Ring Analyzer, where the samples were placed on supports and inserted in the reading compartment, and analyzed directly in the radial direction, using a collimated source of X-ray beams. The density reading was done every $0.4 \mathrm{~mm}$ and obtaining the radial density profiles of the wood was possible using the QMS software.

\subsection{Fiber length and wall thickness}

For the analysis of the radial variation of fiber length and wall thickness, the radial sections that presented the lowest speeds of wave propagation in each disk were selected. In each section, tangential cuts were made every $1 \mathrm{~cm}$, obtaining samples with dimensions $1.0 \times 1.0 \times 3.0 \mathrm{~cm}$. From each sample, wood fragments were cut in the direction of the fibers. The dissociation was carried out according to the methodology described by Franklin (1945). The fragments were stained with $1 \%$ safranin and used to make the semi-permanent slides.

The images were captured using a high-resolution camera coupled to an Olympus CX40 optical microscope connected to the TSView 6.2.4.5 software (Tucsen Imaging Technology CO., Limited). The images were analyzed using the Cell software.

\subsection{Statistical analysis}

Multivariate associations between the variables of interest (propagation speed of acoustic waves, apparent density, fiber wall length and thickness) as a function of planting spacing and radial profile (pith-bark) were evaluated by principal component analysis (PCA), using the PAST 4.02 software. For this, the data contained in the rays common to all analysis were used, that is, those that presented lower wave propagation speeds. In assessing the radial profile, the information was segmented into three parts: i) region close to the pith; ii) intermediate region; and iii) region close to the bark.

\section{RESULTS}

In general, trees in all planting densities evaluated showed high wave propagation speeds, with a minimum and maximum of 1349 and $4176 \mathrm{~m} / \mathrm{s}$, respectively. On average, trees subjected to $5 \times 2$ spacing showed the highest values (Table 1).

Table 1. Descriptive statistics of the speed of acoustic waves propagation and apparent density of Tectona grandis wood under different planting spacing.

\begin{tabular}{|c|c|c|c|c|c|c|c|c|}
\hline \multirow[t]{2}{*}{ Spacing } & \multirow[t]{2}{*}{ Tree } & \multirow[t]{2}{*}{ DBH $(\mathbf{c m})$} & \multicolumn{3}{|c|}{$\begin{array}{l}\text { Speed of Acoustic Waves Propagation } \\
(\mathrm{m} / \mathrm{s})\end{array}$} & \multicolumn{3}{|c|}{ Apparent Density $\left(\mathrm{g} / \mathrm{cm}^{3}\right)$} \\
\hline & & & Min & Average $^{(\mathrm{CV} \%)}$ & $\operatorname{Max}$ & Min & Average $(\mathrm{CV} \%)$ & $\operatorname{Max}$ \\
\hline \multirow{4}{*}{$4 \times 2$} & 1 & 13.81 & 1670 & $1900^{(11.45)}$ & 2602 & 0.204 & $0.537^{(14.19)}$ & 0.768 \\
\hline & 2 & 13.85 & 1643 & $2262^{(31.49)}$ & 4176 & 0.207 & $0.582^{(16.44)}$ & 0.852 \\
\hline & 3 & 15.15 & 1453 & $1823^{(11.74)}$ & 2168 & 0.189 & $0.585^{(14.84)}$ & 0.971 \\
\hline & General & 14.27 & 1453 & $1995^{(24.41)}$ & 4176 & 0.189 & $0.568^{(15.69)}$ & 0.971 \\
\hline \multirow{4}{*}{$5 \times 2$} & 1 & 17.19 & 2061 & $2231^{(9.40)}$ & 2690 & 0.231 & $0.599^{(13.42)}$ & 0.876 \\
\hline & 2 & 16.39 & 1453 & $1558^{(2.64)}$ & 1640 & 0.241 & $0.544^{(17.66)}$ & 0.903 \\
\hline & 3 & 14.80 & 1651 & $2497^{(19.40)}$ & 3377 & 0.277 & $0.539^{(14.09)}$ & 0.802 \\
\hline & General & 16.13 & 1453 & $2092^{(23.85)}$ & 3377 & 0.231 & $0.562^{(15.88)}$ & 0.903 \\
\hline \multirow{4}{*}{$6 \times 2$} & 1 & 21.65 & 1643 & $1971^{(11.41)}$ & 2421 & 0.275 & $0.572^{(15.32)}$ & 0.937 \\
\hline & 2 & 21.33 & 1349 & $1609^{(12.26)}$ & 2099 & 0.305 & $0.605^{(14.41)}$ & 0.872 \\
\hline & 3 & 21.96 & 1518 & $1725^{(5.88)}$ & 1903 & 0.302 & $0.571^{(15.70)}$ & 1.147 \\
\hline & General & 21.63 & 1349 & $1767^{(13.35)}$ & 2421 & 0.275 & $0.581^{(15.40)}$ & 1.147 \\
\hline
\end{tabular}

$\mathrm{DBH}=$ diameter at breast height -1.30 from the ground; $\mathrm{CV}=$ coefficient of variation . 
The radial velocity profiles showed random patterns throughout the analyzed regions, sometimes showing wide variation (Figures $1 \mathrm{~B}, 1 \mathrm{~F}$ ), and sometimes uniformity (Figure $1 \mathrm{E}$ ). There were no marked reductions in propagation speeds that could indicate internal structural problems in the wood of the analyzed trees, which was confirmed after obtaining the discs.

Although the DBH has increased due to the spacing used, the average apparent densities were approximate, with a high amplitude between the minimum and maximum values due to the anatomical characteristics of the species (porosity in a semi-porous ring). The highest densities were observed in trees with $6 \times 2$ spacing (Table 1). From the radial profile of the densities, there was a slight reduction in the pith region and a more evident variation between the growth rings in the regions close to the bark (sapwood). In the initial wood, the density was lower, due to the increase in the diameter of the vessels and the presence of the marginal parenchyma band, gradually increasing at the limits of the rings (Figure 2).
A)

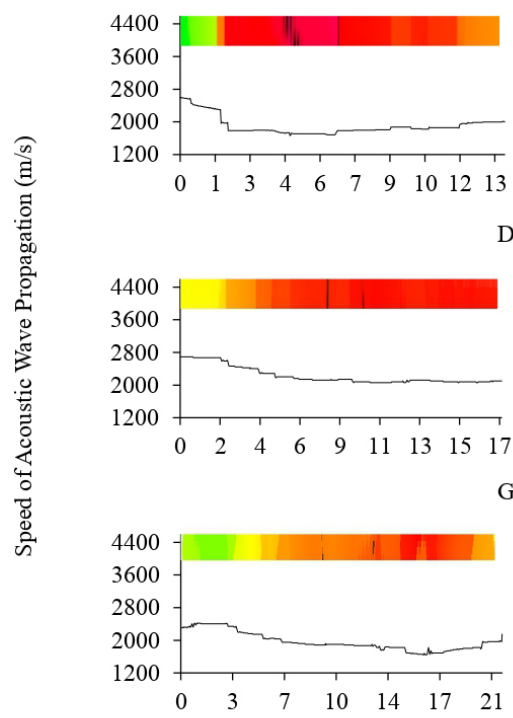

B)

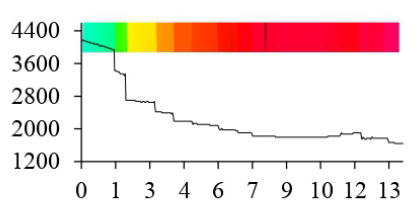

D)

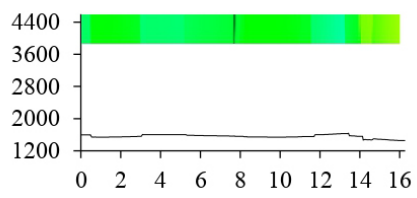

$\mathrm{H})$

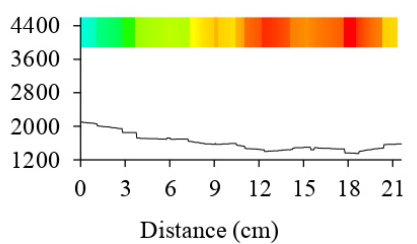

C)

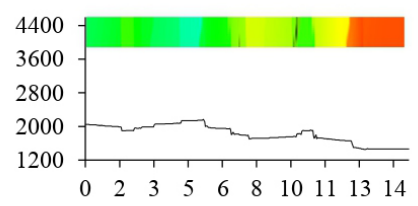

F)

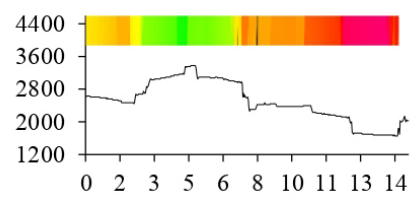

I)

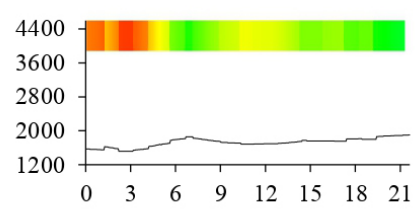

Figure 1. Radial velocity profile (bark-pith-bark direction) of acoustic waves propagation (obtained by impulse tomography) in Tectona grandis wood under different planting spacing. A), B) and C) $=4 \times 2$ spacing; D), E) and F) $=5 \times 2$ spacing; G), H) and I) $=6 \times 2$ spacing.

A)

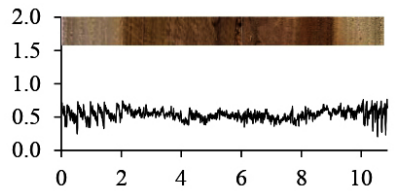

D)

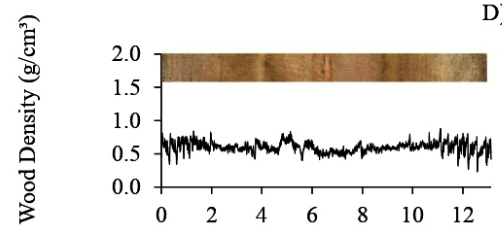

G)

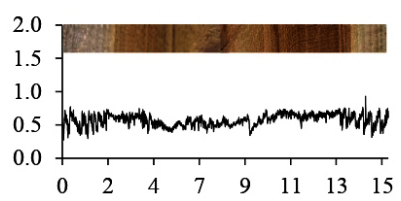

B)

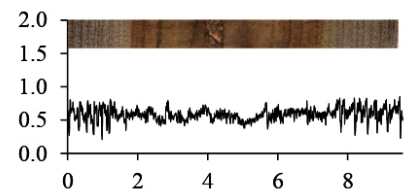

E)

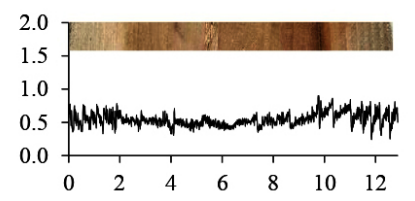

$\mathrm{H})$

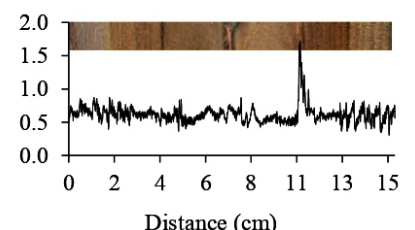

C)

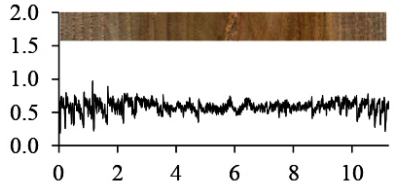

F)

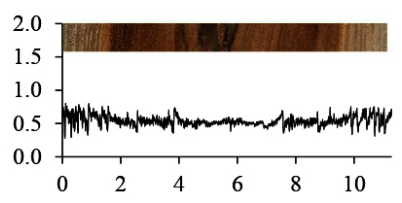

I)

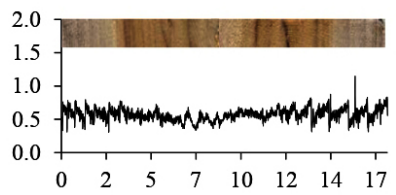

Figure 2. Radial profile (bark-pith-bark direction) of apparent density (obtained by X-ray densitometry) in Tectona grandis wood under different planting spacing. A), B) and C) $=4 \times 2$ spacing; D), E) and F) $=5 \times 2$ spacing; G), H) and I) $=6 \times 2$ spacing. 
Fibers anatomical characteristics showed similar values between the trees of the studied spacing. Larger and thicker fibers were observed in the $6 \times 2$ and $5 \times 2$ spacing, respectively (Table 2).

Increasing patterns of the radial profiles of length and thickness of the fiber wall were observed in all the trees analyzed (pith-bark direction), being in accordance with the expected age (Figure 3).

PCA of the variables of interest, as a function of the spacing, showed that three components explained $90.70 \%$ of the total variation, and the spacing did not show clear patterns of grouping (Figure 4). The variables "fiber length" and "fiber wall thickness" were directly related to each other, that is, longer fibers have thicker walls. The variables "speed of acoustic waves propagation" and "apparent density" showed an inverse relationship with each other, indicating that higher densities implied a reduction in the speed of waves propagation.

Table 2. Descriptive statistics of fiber length and wall thickness of Tectona grandis wood fibers under different planting spacing.

\begin{tabular}{|c|c|c|c|c|c|c|c|}
\hline \multirow{2}{*}{ Spacing } & \multirow{2}{*}{ Tree } & \multicolumn{3}{|c|}{ Fiber Length (mm) } & \multicolumn{3}{|c|}{ Fiber Wall Thickness $(\mu \mathrm{m})$} \\
\hline & & Min & Average $^{(\mathrm{CV} \%)}$ & $\operatorname{Max}$ & Min & Average $^{(\mathrm{CV} \%)}$ & $\operatorname{Max}$ \\
\hline \multirow{4}{*}{$4 \times 2$} & 1 & 0.749 & $0.908^{(19.99)}$ & 1.139 & 3.706 & $4.461^{(10.09)}$ & 4.906 \\
\hline & 2 & 0.748 & $0.963^{(17.89)}$ & 1.222 & 4.456 & $4.990^{(7.14)}$ & 5.436 \\
\hline & 3 & 0.725 & $0.976^{(15.08)}$ & 1.156 & 4.147 & $4.868^{(9.16)}$ & 5.337 \\
\hline & General & 0.725 & $0.950^{(16.82)}$ & 1.222 & 3.706 & $4.778^{(9.58)}$ & 5.436 \\
\hline \multirow{4}{*}{$5 \times 2$} & 1 & 0.686 & $0.856^{(18.92)}$ & 1.143 & 4.123 & $5.105^{(13.02)}$ & 5.997 \\
\hline & 2 & 0.752 & $0.914^{(18.38)}$ & 1.187 & 4.123 & $4.806^{(11.27)}$ & 5.635 \\
\hline & 3 & 0.840 & $1.040^{(15.95)}$ & 1.308 & 4.266 & $4.811^{(10.37)}$ & 5.352 \\
\hline & General & 0.686 & $0.932^{(18.82)}$ & 1.308 & 4.123 & $4.912^{(11.56)}$ & 5.997 \\
\hline \multirow{4}{*}{$6 \times 2$} & 1 & 0.846 & $1.071^{(17.54)}$ & 1.372 & 3.449 & $4.494^{(13.17)}$ & 5.144 \\
\hline & 2 & 0.626 & $0.918^{(18.49)}$ & 1.133 & 3.075 & $4.435^{(18.51)}$ & 5.424 \\
\hline & 3 & 0.850 & $1.074^{(13.04)}$ & 1.350 & 3.413 & $4.856^{(16.80)}$ & 5.860 \\
\hline & General & 0.626 & $1.021^{(17.23)}$ & 1.372 & 3.075 & $4.607^{(16.43)}$ & 5.860 \\
\hline
\end{tabular}

$\mathrm{CV}=$ coefficient of variation.

\section{— Fibre Wall Thickness}

A)

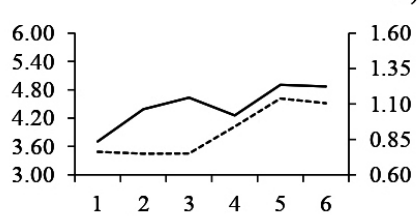

D)

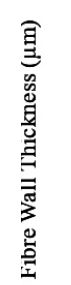

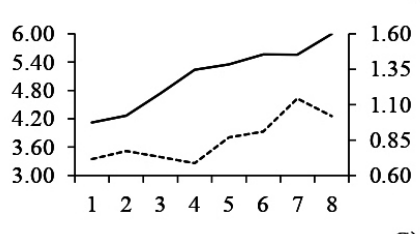

G)

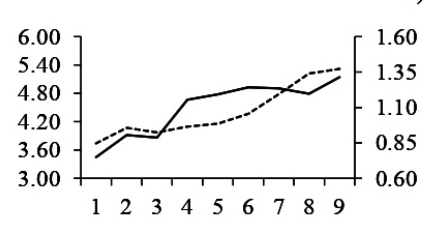

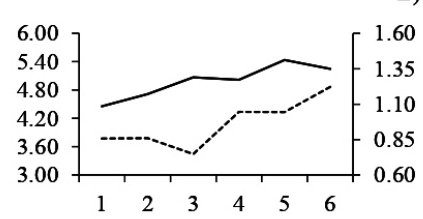

B)

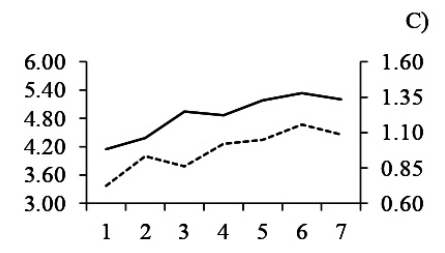

E)
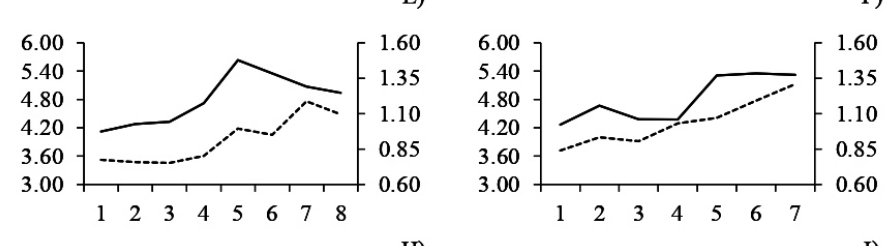

H)
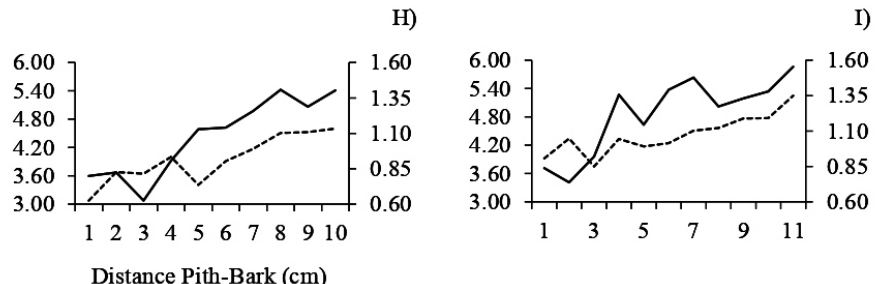

Figure 3. The radial profile of wall thickness and fiber length in Tectona grandis wood under different planting spacing. A), B) and C) = $4 \times 2$ spacing; D), E) and F) $=5 \times 2$ spacing; G), H) and I) $=6 \times 2$ spacing. 


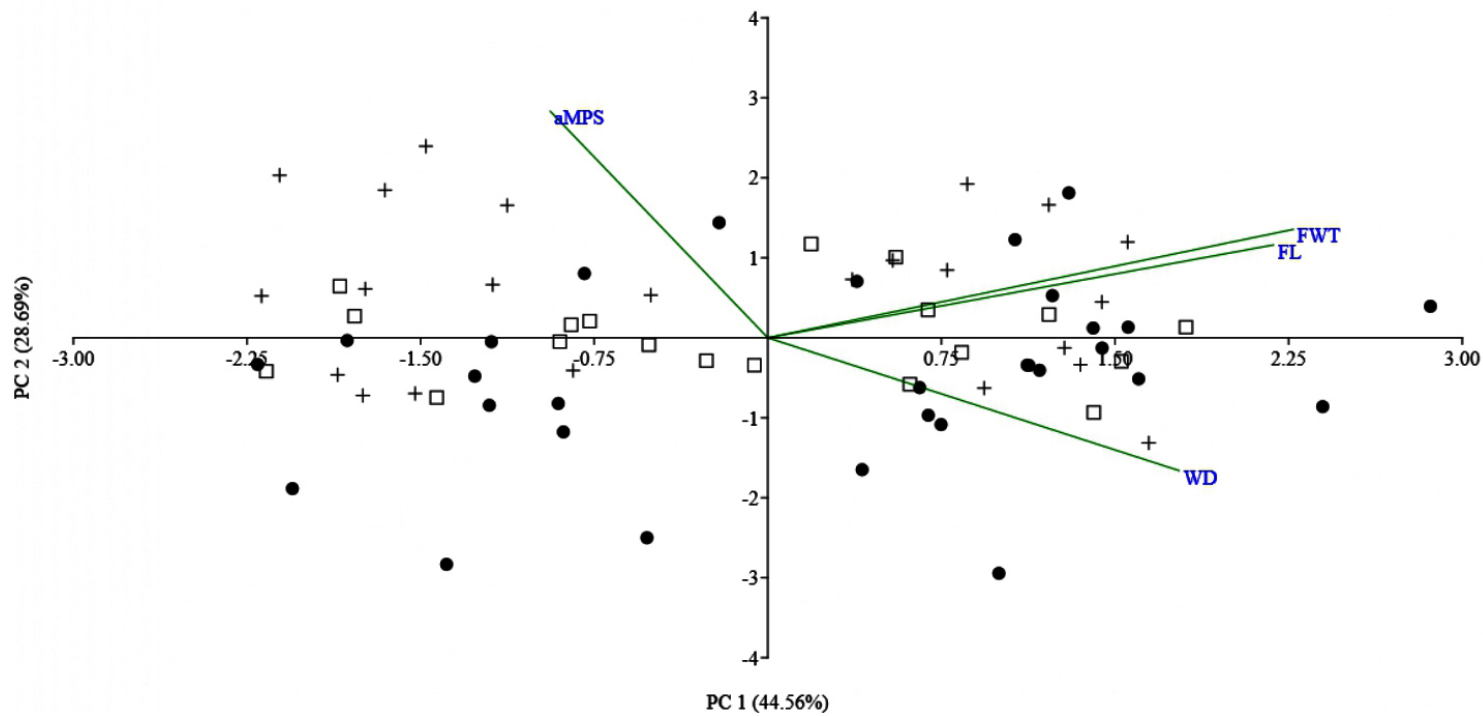

Figure 4. Biplot analysis of the variables of interest as a function of the planting spacing showing the main components that retain the highest percentage of the total variance (73.25\%). Variables "fiber length (FL)" and "fiber wall thickness (FWT)" were more important for component 1. Variable "speed of acoustic waves propagation (aMPS)" was more important for component 2. Only the variable "apparent density (WD)" was not important for the components presented. Legend: ( $\square) 4$ x 2 spacing; (+) 5 x 2 spacing; (•) 6 x 2 spacing.

The first component explained $44.56 \%$ of the total variation and was influenced by the length and wall thickness of the fibers. The second and third components explained $28.69 \%$ and $17.45 \%$ of the variance and were influenced by the speed of acoustic waves propagation and apparent density, respectively (Table 3 ).

PCA of the variables of interest as a function of the radial profile showed that three components explained $92.82 \%$ of the total variation. There was a clustering pattern between the regions close to the pith, intermediate, and close to the bark (Figure 5) which was explained, mainly, by the characteristics of the fibers. The relationship between the variables was similar to that observed in the analysis due to the spacing.

The first component explained $44.84 \%$ of the total variation and was influenced by the length and wall thickness of the fibers. The second and third components explained 31.93\% and $16.05 \%$ of the variance and were influenced by the speed of acoustic waves propagation and apparent density, respectively (Table 4).

Table 3. Summary of the main components (variables of interest as a function of planting spacing) and their respective proportions of total explained variance and loads showing (in bold) the variables of importance for each component.

\begin{tabular}{ccccccccc} 
& \multicolumn{3}{c}{ Summary } & \multicolumn{3}{c}{ Loadings } \\
\cline { 2 - 9 } & $\lambda$ & Variance $(\%)$ & $\begin{array}{c}\text { Cumulative } \\
(\%)\end{array}$ & FL & FWT & aMPS & WD \\
\hline 1 & 1.78 & 44.56 & 44.56 & $\mathbf{0 . 5 8}$ & $\mathbf{0 . 6 1}$ & -0.25 & 0.48 \\
2 & 1.15 & 28.69 & 73.25 & 0.31 & 0.36 & $\mathbf{0 . 7 6}$ & -0.44 \\
3 & 0.70 & 17.45 & 90.70 & -0.47 & 0.13 & 0.53 & 0.28 & 0.31 \\
4 & 0.37 & 9.30 & 100.00 & 0.59 & -0.69 & 0.28 \\
\hline
\end{tabular}

$\lambda=$ eigenvalues; $\mathrm{FL}=$ fiber length; FWT = fiber wall thickness; aMPS = speed of acoustic waves propagation; $\mathrm{WD}=$ apparent density. 


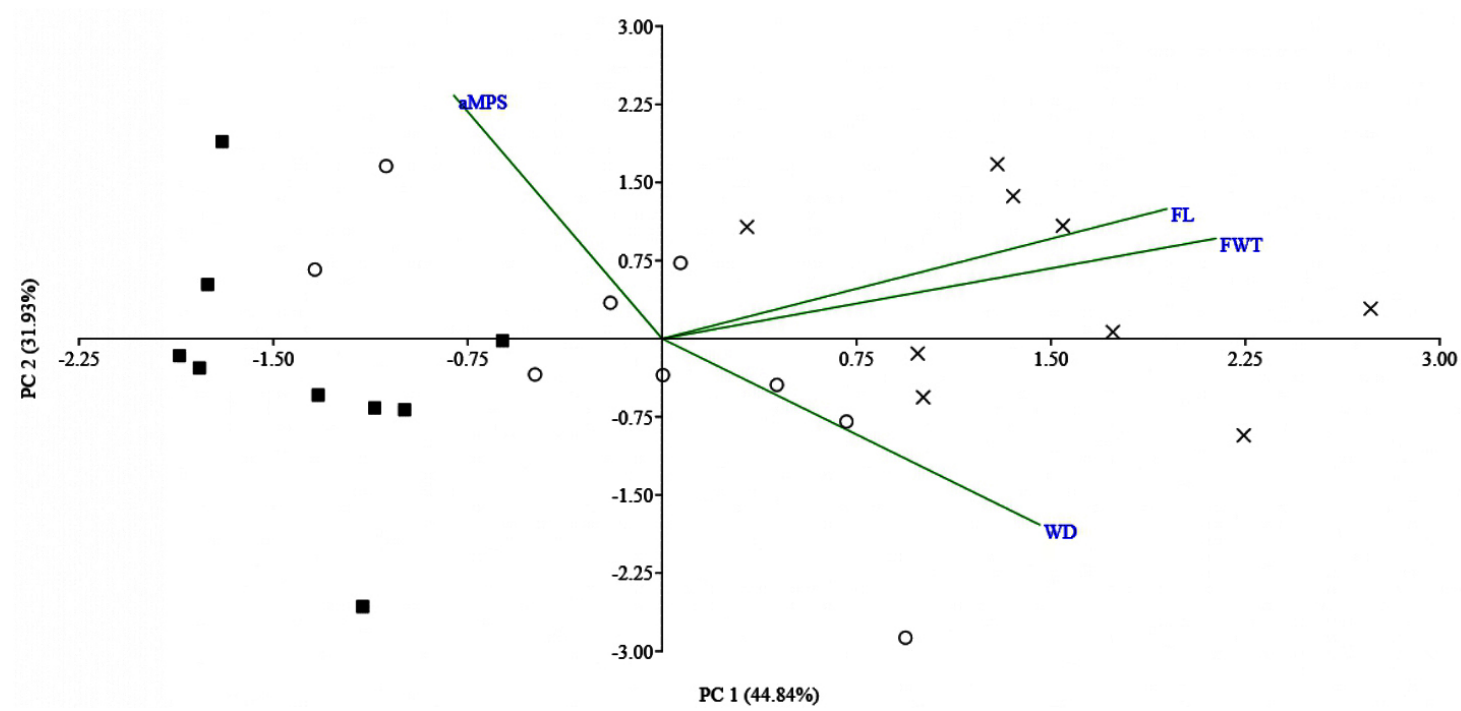

Figure 5. Biplot analysis of the variables of interest as a function of the radial profile showing the main components that retain the highest percentage of the total variance (76.77\%). Variables "fiber length (FL)" and "fiber wall thickness (FWT)" were more important for component 1. Variable "speed of acoustic waves propagation (aMPS)" was more important for component 2. Only the variable "apparent density (WD)" was not important for the components presented. Legend: (-) pith; (०) intermediate; (x) bark.

Table 4. Summary of the main components (variables of interest as a function of the radial profiles) and their respective proportions of total explained variance and loads showing (in bold) the variables of importance for each component.

\begin{tabular}{|c|c|c|c|c|c|c|c|}
\hline \multirow{2}{*}{ PC } & \multicolumn{3}{|c|}{ Summary } & \multicolumn{4}{|c|}{ Loadings } \\
\hline & $\lambda$ & Variance (\%) & Cumulative (\%) & FL & FWT & aMPS & WD \\
\hline 1 & 1.79 & 44.84 & 44.84 & 0.58 & 0.64 & -0.24 & 0.44 \\
\hline 2 & 1.28 & 31.93 & 76.77 & 0.37 & 0.29 & 0.70 & -0.54 \\
\hline 3 & 0.64 & 16.05 & 92.82 & -0.42 & 0.19 & 0.63 & 0.63 \\
\hline 4 & 0.29 & 7.18 & 100.00 & 0.59 & -0.69 & 0.24 & 0.35 \\
\hline
\end{tabular}

$\lambda=$ eigenvalues; $\mathrm{FL}=$ fiber length; FWT $=$ fiber wall thickness; aMPS = speed of acoustic waves propagation; $\mathrm{WD}=$ apparent density.

\section{DISCUSSION}

Acoustic waves propagation in the wood can be influenced by several factors, among which the following stand out: physical and anatomical properties of the wood (density, moisture content and structure of the growth rings, mainly); geometric characteristics of the study material; environmental conditions (temperature, relative humidity and mechanical loads); and characteristics of the equipment used (Bucur, 2006). The high amplitude observed in the propagation of acoustic waves in the trees under study demonstrates the differences in transmission along the wood. As it is an experimental planting, in which the selected trees were exposed to the same environmental conditions and evaluated with the same equipment, it is likely that the natural variability of the wood has influenced the observed patterns of transmission.

Youth in teak plantations extend from 15 to 25 years, depending on the growth rate and the intrinsic characteristics of the trees, in addition to the specificities of the planting location (Bhat et al., 2001; Darmawan et al., 2015). Considering this information, the material analyzed in this study is composed exclusively of juvenile wood. The juvenile portion of the tree is located close to the pith and is characterized by progressive changes both in the cellular characteristics and in the technological properties of wood (Silva et al., 2020). When compared to adult wood, juvenile hardwood is composed of shorter fibers with thin walls, a high microfibrillar angle, lower densities and mechanical resistance properties (Palermo et al., 2015). The increasing radial profile of wall thickness and fiber length (pith-bark direction) observed in this study corroborates the totality of juvenile wood present in the discs. Studies have shown that juvenile wood has lower acoustic wave propagation speeds, which can be confused with the presence of deteriorated areas (Brancheriau et al., 2012; Palma et al., 2018).

The acoustic waves obtained by the equipment used in this study were generated mechanically from a transmitting sensor until reaching the other receiving sensors (Musat, 2017). In 
intact woods, the transmission time of the wave from one sensor to another is shorter when compared to woods with some deteriorated region. That is, if there is an internal lesion in the wood, the wave will take longer to reach the receiving sensor, consequently reducing its propagation speed (Liang $\& \mathrm{Fu}, 2014)$. Despite the speed variation in the teak discs, no injuries were observed in the evaluated sections.

The radial profile of apparent density presented by the trees studied showed that, in sapwood region, the distinction between early and latewood is more evident. Possibly, this more evident demarcation is due to the low concentration of extratives, which are present in high concentrations in the heartwood and can influence the density of this region (Thulasidas \& Baillères, 2017). In addition, in the early years of development of teak trees, in fast-growing plantations, the ring boundary is not clearly distinguishable by X-ray densitometry, and joint monitoring of microscopic analysis is advised (Gaitan-Alvarez et al. 2019). This pattern is expected due to the fast to medium growth that the species shows; at suitable sites and under appropriate management practices it can grow between 3 to $5 \mathrm{~cm}$ in diameter at 3 to 6 years of age (Jerez-Rico \& Coutinho, 2017). In this study, the increase in spacing between trees allowed greater increments in diameter without, however, influencing the radial density profile.

\section{CONCLUSIONS}

Teak trees at 11 years old have typical characteristics of juvenile wood and, therefore, are mainly influenced by the radial variation (pith - bark). Planting densities $4 \times 2,5 \times 2$ and $6 \times 2$ provide an increase in diameter without, however, impacting the speed of acoustic waves propagation, density and fibers anatomy. Thus, it is recommended to monitor the growth of the trees in order to check if the presence of adult wood allows greater sensitivity of response to the silvicultural treatments used.

\section{ACKNOWLEDGEMENTS}

This study was financed in part by the Coordenação de Aperfeiçoamento de Pessoal de Nível Superior - Brasil (CAPES) - Finance Code 001.

\section{SUBMISSION STATUS}

Received: 5 Apr. 2021

Accepted: 14 Oct. 2021

Associate editor: José Luis Louzada

\section{CORRESPONDENCE TO}

\section{João Vicente de Figueiredo Latorraca}

Universidade Federal Rural do Rio de Janeiro, Instituto de Florestas, Rod. BR 465, Km 07, CEP 23890-000, Seropédica, RJ, Brasil.

e-mail: latorraca@hotmail.com

\section{REFERENCES}

Alvares CA, Stape JL, Sentelhas PC, de Moraes Gonçalves JL, Sparovek G. Köppen's climate classification map for Brazil. Meteorologische Zeitschrift 2013, 22(6):711-728.

Bhat KM, Priya PB, Rugmini P. Characterisation of juvenile wood in teak. Wood Science and Technology 2001, 34:517-532.

Brancheriau L, Ghodrati A, Gallet P, Thaunay P, Lasaygues P. Application of ultrasonic tomography to characterize the mechanical state of standing trees (Picea abies). Journal of Physics: Conference Series 2012, 353:1-13.

Bucur V. Part II Material Characterization. Theory of and Experimental Methods for the Acoustic Characterization of Wood. In: Timell TE, Wimmer R, editors. Acoustics of Wood. 2nd ed. New York: Springer-Verlag Berlin Heidelberg; 2006.

Cavalcante Pereira L, Silva Filho DF, Tomazello Filho M, Couto HTZ, Moreira JMMÁP, Polizel JL. Tomografia de Impulso para Avaliação do Interior do Lenho de Árvores. Revista da Sociedade Brasileira de Arborização Urbana 2007, 2(2):65-75.

Darmawan W, Nandika D, Sari RK, Sitompul A, Rahayu I, Gardner D. Juvenile and Mature Wood Characteristics of Short and Long Rotation Teak in Java. IAWA Journal 2015, 36(4):428-442.

De Moraes Gonçalves JL, Stape JL, Laclau JP, Smethurst P, Gava JL. Silvicultural effects on the productivity and wood quality of eucalypt plantations. Forest Ecology and Management 2004, 193(1-2):45-61.

Franklin, G. L. Preparation of thin sections of synthetic resins and wood-resin composites, and a new macerating method for wood. Nature 1945, 155(3924):51.

Gaitan-Alvarez J, Moya R, Berrocal A. The use of X-ray densitometry to evaluate the wood density profile of Tectona grandis trees growing in fast-growth plantations. Dendrochronologia 2019, 55:71-79.

IBÁ. Relatório Anual 2019. [cited 2020 dec. 11]. Available from: https:// iba.org/datafiles/publicacoes/relatorios/relatorioiba2019-final.pdf.

Jacquin P, Longuetaud F, Leban JM, Mothe F. X-ray microdensitometry of wood: A review of existing principles and devices. Dendrochronologia 2017, 42:42-50.

Jerez-Rico M, Coutinho SA. Planted Teak Forests. In: Kollert W, Kleine M, editors. The Global Teak Study: Analysis, Evaluation and Future Potential of Teak Resources. 36 ed. Vienna: IUFRO, International Union of Forest Research Organizations; 2017.

Khaing N, Min Oo M, Tun TN, Lwin O, Minn Y, Kleine M. Natural Teak Forests - Silviculture and Stand Management. In: Kollert W, 
Kleine M, editors. 36 ed. Vienna: IUFRO, International Union of Forest Research Organizations; 2017.

Kollert W, Cherubini L. Teak Resources and Market Assessment 2010. FAO Planted Forests and Trees Working Paper FP/47/E 2012, 3(January):16-17.

Kollert W, Kleine M. The Global Teak Study. Analysis, Evaluation and Future Potential of Teak Resources. 36 ed. Vienna: IUFRO, International Union of Forest Research Organizations; 2017.

Liang S, Fu F. Effect of Sensor Number and Distribution on Accuracy Rate of Wood Defect Detection with Stress Wave Tomography. Wood Research 2014, 59(4):521-532.

Makinen H, Hynynen J, Penttila T. Effect of thinning on wood density and tracheid properties of Scots pine on drained peatland stands. Forestry 2015, 88(3):359-367.

Medeiros RGS, Nascimento CC, Barros SVS, Kroessin A, Paula EVCM, Higuchi H. Tomografia de impulso na avaliação da sanidade e rendimento de Micrandopsis scleroxylon W. Rodr. Nativa: Pesquisas Agrárias e Ambientais 2017, 5:649-655.

Mendes FH, Silva Filho DF. Frequency variation of mechanical waves of the impulse tomograph based on geographic north. Scientia Forestalis 2019, 47(122):353-358.

Moya R, Bond B, Quesada H. A review of heartwood properties of Tectona grandis trees from fast-growth plantations. Wood Science and Technology 2014, 48(2):411-433.

Musat EC. Analysing the Sound Spped Through the Wood of Horse Chestnut Trees (Aesculus hippocastanum Lin.). Bulletin of the Transsilvania University of Brasov 2017, 10(59):55-66.

Pagotto MA, DeSoto L, Carvalho A, Nabais C, Tomazello Filho M, Ribeiro A, Lisi CS. Evaluation of X-ray densitometry to identify tree-ring boundaries of two deciduous species from semi-arid forests in Brazil. Dendrochronologia 2017, 42:94-103.

Palermo GPM, Latorraca JVF, Carvalho AM, Calonego FW, Severo ETD. Anatomical properties of Eucalyptus grandis wood and transition age between the juvenile and mature woods. European Journal of Wood and Wood Products 2015, 73:775-780.

Palma SSA, Gonçalves R, Trinca AJ, Costa CP, Reis MN, Martins GA. Interference from Knots, Wave Propagation Direction, and Effect of Juvenile and Reaction Wood on Velocities in Ultrasound Tomography. BioResources 2018, 13(2):2834-2845.

Rollo FMA, Soave Junior MA, Viana SM, Rollo LCP, Couto HTZ, Silva Filho DF. Comparação entre leituras de resistógrafo e imagens tomográficas na avaliação interna de troncos de árvores. Cerne 2013, 19(2):331-337.

Silva JGM, Vidaurre GB, Ballarin AW, Oliveira JTS. Demarcação e propriedades dos lenhos juvenil e adulto de eucalipto. In: Vidaurre GB, Moulin JC, Carneiro ACO, editors. Qualidade da madeira de eucalipto proveniente de plantações no Brasil. Vitória: EDUFES; 2020.

Singh J, Pandey SK, Rai HK, Nath V, Poojan S. Influence of Spacing and Planting System on Light Interception, Physiological Parameters, Yield and Quality of Litchi cv. Shahi. International Journal of Current Microbiology and Applied Sciences 2020, 9(9):1214-1226.

Thulasidas PK, Baillères H. Wood Quality for Advanced Uses of Teak from Natural and Planted Forests. In: Kollert W, Kleine M, editors. The Global Teak Study: Analysis, Evaluation and Future Potential of Teak Resources. 36 ed. Vienna: IUFRO, International Union of Forest Research Organizations; 2017.

Tun TN, Guo J, Fang S, Tian Y. Planting spacing affects canopy structure, biomass production and stem roundness in poplar plantations. Scandinavian Journal of Forest Research 2018, 33(5):464-474. 